\title{
Resistencia antibiótica en infecciones urinarias en niños atendidos en una institución privada, periodo 2007 - 2011
}

\author{
Antibiotic resistance of pathogens causing urinary tract infections in children attended at a private \\ institution from 2007-2011
}

Fernando Polanco ${ }^{1}$, Reyner Loza ${ }^{2,3}$.

RESUMEN

La resistencia antibiótica es un serio problema de salud, sobre todo en pacientes con recurrencia de episodios y anomalías del sistema urinario. Objetivo: Describir el patrón de resistencia antibiótica de las bacterias causantes de la infección del tracto urinario (ITU) como primer episodio, recurrente o complicada en niños menores de 5 años. Material y métodos: Estudio tipo serie de casos observacional, retrospectivo y descriptivo. Se revisaron las historias clínicas de los pacientes con diagnóstico de ITU con cultivo de orina positivo, durante un periodo de 5 años en una institución de salud privada. Resultados: Se incluyeron 111 niños de 1 mes a 5 años; 97 (87,4\%) fueron mujeres; $68(61,3 \%)$ fueron lactantes; hubieron 77 pacientes con ITU, 34 con ITU recurrente o complicada. Escherichia coli $(63,1 \%)$ fue el microorganismo más frecuente en todos los grupos. La resistencia antibiótica fue: ampicilina $80,6 \%$, cefalotina 59\%, amoxicilina/clavulánico 55,4\%, trimetoprima-sulfametoxazol 51,6\%, ácido nalidixico 51\%, cefalexina $40 \%$, cefotaxima $31 \%$, cefuroxima $29,8 \%$, ceftriaxona $28,6 \%$, ceftazidima $27,3 \%$, norfloxacino $21,2 \%$, ciprofloxacino $21,1 \%$; y con menos resistencia fueron nitrofurantoína $17 \%$, gentamicina $13,2 \%$, amikacina $1 \%$. Conclusiones: La resistencia antimicrobiana para los antibióticos usados para el tratamiento de ITU es alta para las aminopenicilinas, sulfas, cefalosporinas de primera, segunda y tercera generación así como quinolonas; los aminoglucósidos aún presentan muy baja resistencia porque lo que serían útiles para la terapia de primera elección.

PALABRAS CLAVE: Resistencia a medicamentos, antibacterianos, infección, niño. (Fuente: DeCS BIREME)

\section{SUMMARY}

Antibiotic resistance is a major public health concern among patients with urinary tract infections (UTI), particularly among those with recurrent infections and in those with urinary tract anomalies. Objective: Describe the antimicrobial resistant pattern of bacterial pathogens causing UTI including fist episodes, recurrent episodes and complicated UTIs in children below 5 years of age. Methods: Retrospective case-series over a 5-year period that included patients with confirmed UTI whose charts were reviewed to extract relevant data. Results: A total of 111 children were included from 1 month to 5 years of age; 97 (87,4\%) were females; 68 (61,3\%) were breastfed; $77 \%$ had UTI; 34 had recurrent or complicated UTI. Escherichia coli $(63,1 \%)$ was the most common pathogen in all age groups, and the antibiotic resistance profile was as follows: $80,6 \%$ to ampicillin, $59 \%$ to cefalotine, $55,4 \%$ to amoxicillin-clavunaic acid, $51,6 \%$ to trimethoprim-sulfamethoxazol, $51 \%$ to nalidix acid, $40 \%$ to cephalexin, $31 \%$ to cefotaxime, $29,8 \%$ to cefuroxime, $28,6 \%$ to ceftriaxone, $27,3 \%$ to ceftazidime, $21,2 \%$ to norfloxacin, $21,1 \%$ to ciprofloxacin, $17 \%$ to nitrofurantoin, $13,2 \%$ to gentamycin and $1 \%$ to amikacin. Conclusions: There is a high

Médico Cirujano. Facultad Medicina Alberto Hurtado, Universidad Peruana Cayetano Heredia. Lima, Perú.

Nefrólogo Pediatra. Médico Asistente Servicio Nefrología Pediátrica, Hospital Nacional Cayetano Heredia. Unidad de

Nefrología Pediátrica, Clínica Médica Cayetano Heredia. Lima, Perú.

Profesor Auxiliar. Departamento Pediatría, Facultad Medicina Alberto Hurtado, Universidad Peruana Cayetano Heredia. Lima, Perú. 
antibiotic resistance profile to most of the common antimicrobials used to treat UTIs. Aminolgycosides are the first choice based on their antibiotic resistant profile.

KEYWORDS: Drug resistance, Anti-bacterial agents, infection, urinary system, child. (Source: MeSH NLM)

\section{INTRODUCCIÓN}

En los últimos años se ha observado en muchos hospitales y clínicas privadas variaciones significativas en la susceptibilidad microbiana, observándose la aparición progresiva de resistencia a las cefalosporinas de primera, segunda y tercera generación, fluoroquinolonas y otros antibióticos comúnmente empleados en el tratamiento empírico de la infección del tracto urinario (ITU) extra hospitalaria (1). Esta aparición de resistencia se está convirtiendo en un problema de salud de difícil manejo y sugiere que se deben revisar las pautas de tratamiento de primera y segunda elección a fin de hacer un uso más racional de los antibióticos.

La resistencia Bacteriana en nuestro medio hospitalario actualmente es un problema con una serie de bacterias, principalmente las Gram negativas. En un estudio previo, Escherichia coli tuvo una sensibilidad a ciprofloxacino en el $26 \%$ de los casos y a ceftriaxona en el $43 \%$, por lo que los autores no recomiendan su uso como terapia empírica (2). Del mismo modo se encontró una resistencia menor al 10\% para amikacina (3).

En pacientes con ITU complicada (malformaciones, cateterización, falla renal crónica, inmunosupresión, trasplante renal, hemodiálisis y diálisis peritoneal) e ITU recurrente la resistencia a ampicilina fue $73 \%$, ceftriaxona $11,8 \%$, cefalexina $41,1 \%$, ciprofloxacino $3,8 \%$, gentamicina $43,2 \%$, meropenen $2 \%$, ácido nalidixico $29,3 \%$, nitrofurantoína $13,3 \%$, norfloxacino $11 \%$ y trimetoprima-sulfametoxazol 59,5\% (4).

El patrón de resistencia puede variar en diferentes estudios y a lo largo del tiempo por lo que se realizó este estudio cuyo objetivo fue describir los patrones de resistencia antibiótica de las bacterias causantes de infecciones urinarias como primer episodio, recurrente o complicada en niños menores de 5 años en una institución privada de Lima.

\section{MATERIAL Y MÉTODOS}

\section{Diseño y población de estudio}

Estudio tipo serie de casos, descriptivo y retrospectivo. Se revisaron las historias clínicas de los pacientes atendidos en el periodo de enero de 2007 a diciembre de 2011 en la unidad operativa de Nefrología Pediátrica y en el Laboratorio Clínico de la Clínica Médica Cayetano Heredia (CMCH), con diagnóstico de ITU atendidos en emergencia o consultorio externo.

\section{Criterios de selección}

Los criterios de inclusión fueron: pacientes con edad mayor de 1 mes y menor de 5 años con urocultivo positivo tomado por punción suprapúbica, cateterismo, frasco o bolsita colectora de orina. Los criterios de exclusión fueron: haber recibido antibióticoterapia dentro de las 48 horas previas a la toma de urocultivo; tener desnutrición de III grado; y ser inmunocomprometidos.

\section{Definiciones operacionales}

Se definió ITU primer episodio como el primer cuadro clínico compatible y urocultivo positivo; ITU recurrente la presencia de dos o más infecciones en 6 meses o más de 3 infecciones en un año con urocultivo positivo e ITU complicada a la infección en pacientes con alguna anomalía funcional o estructural del sistema genitourinario.

Se consideró urocultivo positivo como el recuento de colonias $>1000 \mathrm{UFC} / \mathrm{ml}$ en orina recolectada con aspiración suprapúbica, $>50000 \mathrm{UFC} / \mathrm{ml}$ en orina obtenida con catéter, y $>100000 \mathrm{UFC} / \mathrm{ml}$ en orina colectada en frasco o bolsita colectora, de una bacteria uropatógena (5). En los casos en lo que no se especificó la forma de colección de muestra se consideró como positivo si el número de colonias fue mayor a 100000 $\mathrm{UFC} / \mathrm{ml}$.

Se utilizó la técnica bioquímica estándar para la identificación de microorganismos. Para determinar la susceptibilidad antibiótica se empleó el método de difusión en disco. Para la detección de BLEE se utilizó la técnica de doble disco. Para la confirmación de la presencia de $\beta$-lactamasa de espectro extendido, se usaron discos de Amoxicilina/Acido Clavulánico (20/10 mg), Ceftazidima (30 mg) y/o Cefotaxima (30 $\mathrm{mg})$ y/o Aztreonam $(30 \mathrm{mg}$ ) y/o Ceftriaxona, método propuesto por la Sociedad Francesa de Microbiología (6). 


\section{Análisis estadístico}

Los datos fueron recolectados y almacenados en una matriz de datos del programa SPSS versión 2013. Se utilizó estadística descriptiva mediante el cálculo de frecuencias relativas de cada variable.

El estudio tuvo revisión completa y fue aprobado por el comité de ética de la Universidad Peruana Cayetano Heredia.

\section{RESULTADOS}

Se incluyeron 111 pacientes que cumplieron con los criterios de selección. Noventa y siete $(87,4 \%)$ fueron mujeres; $68(61,3 \%)$ fueron lactantes y 43 (38,7\%) preescolares; 77 correspondieron a primer episodio y 34 a ITU recurrente o complicada (Tabla 1).

La mayor parte de pacientes fueron lactantes mujeres, $40(36 \%)$ tuvieron ITU primer episodio y el

Tabla 1. Distribución por sexo, diagnóstico y edad.

\begin{tabular}{lcccccc}
\hline & \multicolumn{2}{c}{ Lactantes } & \multicolumn{2}{c}{ Pre escolares } & \multicolumn{2}{c}{ TOTAL } \\
\cline { 2 - 6 } & $\mathbf{F ~ ( \% )}$ & $\mathbf{M ~ ( \% )}$ & $\mathbf{F ~ ( \% )}$ & $\mathbf{M ~ ( \% )}$ & $\mathbf{F ~ ( \% )}$ & M (\%) \\
\hline Primera infección & $40(68,9)$ & $7(70,0)$ & $26(66,7)$ & $4(100,0)$ & $66(68,0)$ & $11(78,6)$ \\
ITU complicada/ recurrente & $18(31,1)$ & $3(30,0)$ & $13(33,3)$ & 0 & $31(32,0)$ & $3(21,4)$ \\
Total & 58 & 10 & 39 & 4 & 97 & 14 \\
\hline
\end{tabular}

ITU: Infección del tracto urinario.

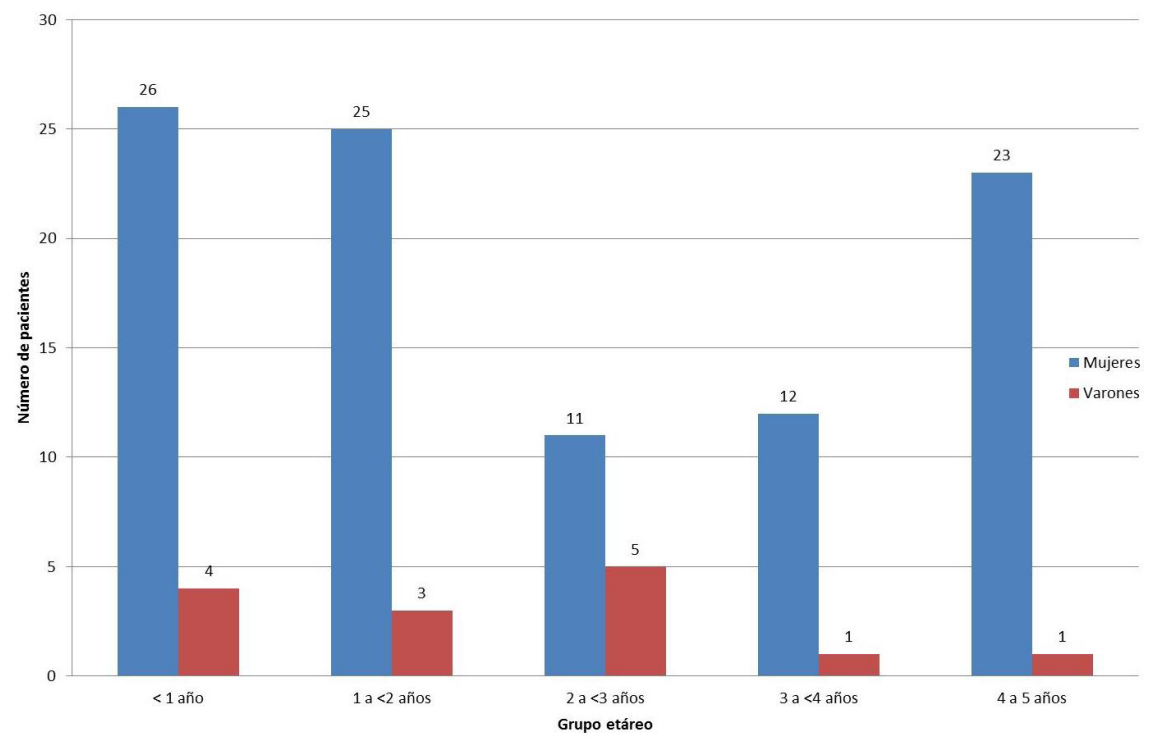

Gráfico 1. Distribución por edad y sexo de los niños con infección urinaria.

Tabla 2. Frecuencia de microorganismos aislados por tipo de ITU.

\begin{tabular}{lcc}
\hline \multicolumn{1}{c}{ Bacteria } & ITU primer episodio (\%) & $\begin{array}{c}\text { ITU complicada o } \\
\text { recurrente (\%) }\end{array}$ \\
\hline Escherichia coli & $61(79,2)$ & $18(53)$ \\
Proteus mirabilis & $6(7,8)$ & $5(14,7)$ \\
Klebsiella pneumoniae & $4(5,2)$ & $3(8.8)$ \\
Enterococcus sp. & $1(1,3)$ & $5(14,7)$ \\
Pseudomonas aeruginosa & - & $2(5,9)$ \\
Staphylococcus sp. & $5(6,5)$ & $1(2,9)$ \\
Total & $77(100)$ & $34(100)$ \\
\hline
\end{tabular}

ITU: Infección del tracto urinario. 
Tabla 3. Susceptibilidad bacteriana a los antibióticos según el tipo de ITU..

\begin{tabular}{|c|c|c|c|c|c|c|c|c|c|c|c|c|}
\hline \multirow{2}{*}{ Antibiótico } & \multicolumn{3}{|c|}{$\begin{array}{l}\text { ITU primer } \\
\text { episodio }\end{array}$} & \multicolumn{3}{|c|}{ ITU Complicada } & \multicolumn{3}{|c|}{ ITU Recurrente } & \multicolumn{3}{|c|}{ TOTAL } \\
\hline & $\mathbf{R}$ & $\mathbf{I}$ & $\mathbf{S}$ & $\mathbf{R}$ & $\mathbf{I}$ & $\mathbf{S}$ & $\mathbf{R}$ & I & $\mathbf{S}$ & $\mathbf{R}$ & $\mathbf{I}$ & $\mathbf{S}$ \\
\hline Ciprofloxacino & 13 & 0 & 66 & 2 & 0 & 7 & 8 & 0 & 14 & 23 & 0 & 87 \\
\hline Norfloxacino & 13 & 0 & 63 & 4 & 0 & 14 & 7 & 0 & 12 & 24 & 0 & 89 \\
\hline Ceftriaxona & 8 & 0 & 35 & 6 & 0 & 4 & 7 & 0 & 8 & 21 & 0 & 47 \\
\hline Cefotaxima & 8 & 0 & 28 & 4 & 0 & 8 & 8 & 0 & 7 & 20 & 0 & 43 \\
\hline Cefalitina & 31 & 4 & 26 & 6 & 0 & 1 & 12 & 0 & 3 & 49 & 4 & 30 \\
\hline Ampicilina & 40 & 0 & 11 & 4 & 0 & 1 & 14 & 0 & 2 & 58 & 0 & 14 \\
\hline Ácido nalidixico & 32 & 2 & 37 & 4 & 0 & 4 & 13 & 0 & 4 & 49 & 2 & 45 \\
\hline Amikacina & 1 & 0 & 70 & 0 & 0 & 8 & 0 & 0 & 21 & 1 & 0 & 99 \\
\hline Gentamicina & 10 & 0 & 65 & 1 & 0 & 8 & 3 & 0 & 19 & 14 & 0 & 92 \\
\hline Nitrofurantoína & 9 & 0 & 65 & 4 & 0 & 5 & 5 & 0 & 17 & 18 & 0 & 87 \\
\hline Ampicilina/Sulbactama & 1 & 1 & 65 & 0 & 0 & 5 & 0 & 0 & 17 & 1 & 1 & 87 \\
\hline Amoxicilina/Clavulánico & 30 & 7 & 31 & 5 & 0 & 3 & 16 & 0 & 0 & 51 & 7 & 34 \\
\hline Trimetoprim/Sulfametoxazol & 34 & 0 & 36 & 2 & 0 & 5 & 13 & 0 & 5 & 49 & 0 & 46 \\
\hline Ceftazidima & 6 & 0 & 16 & 2 & 0 & 5 & 4 & 0 & 3 & 12 & 0 & 24 \\
\hline Cefuroxima & 15 & 0 & 49 & 2 & 0 & 2 & 8 & 0 & 8 & 25 & 0 & 59 \\
\hline Aztreonam & 9 & 0 & 60 & 2 & 0 & 5 & 7 & 0 & 12 & 18 & 0 & 77 \\
\hline
\end{tabular}

Tabla 4. Frecuencia de resistencia antibiótica bacteriana en nuestro medio en poblaciones pediátricas con infección del tracto urinario no complicada ni recurrente.

\begin{tabular}{lccc}
\hline & Chiarella1990(1) & Lucana 2008 (7) & Polanco 2013* \\
\hline Ácido nalidixico & $9 \%$ & $28,9 \%$ & $44,3 \%$ \\
Amikacina & $4 \%$ & $23,7 \%$ & $1,4 \%$ \\
Amoxicilina/Ac.Clavulánico & - & - & $43,3 \%$ \\
Ampicilina/Sulbactam & - & - & $50 \%$ \\
Ampicilina & $82 \%$ & $45,8 \%$ & $78 \%$ \\
Cefalotina & $18 \%$ & & $50 \%$ \\
Ceftazidima & $0 \%$ & $43,3 \%$ & $19,4 \%$ \\
Ceftriaxona & $0 \%$ & $48,7 \%$ & $16,7 \%$ \\
Cefuroxima & - & & $23,4 \%$ \\
Ciprofloxacino & - & $22,2 \%$ & $15,6 \%$ \\
Gentamicina & $0 \%$ & $14,8 \%$ & $12,3 \%$ \\
Nitrofurantoína & $6 \%$ & $23,2 \%$ & $11,1 \%$ \\
Norfloxacino & $0 \%$ & $8,3 \%$ & $16,2 \%$ \\
Sulfametoxazol/Trimetoprima & $53 \%$ & $40,6 \%$ & $48,6 \%$ \\
\hline
\end{tabular}

*Resultados de nuestra serie. 


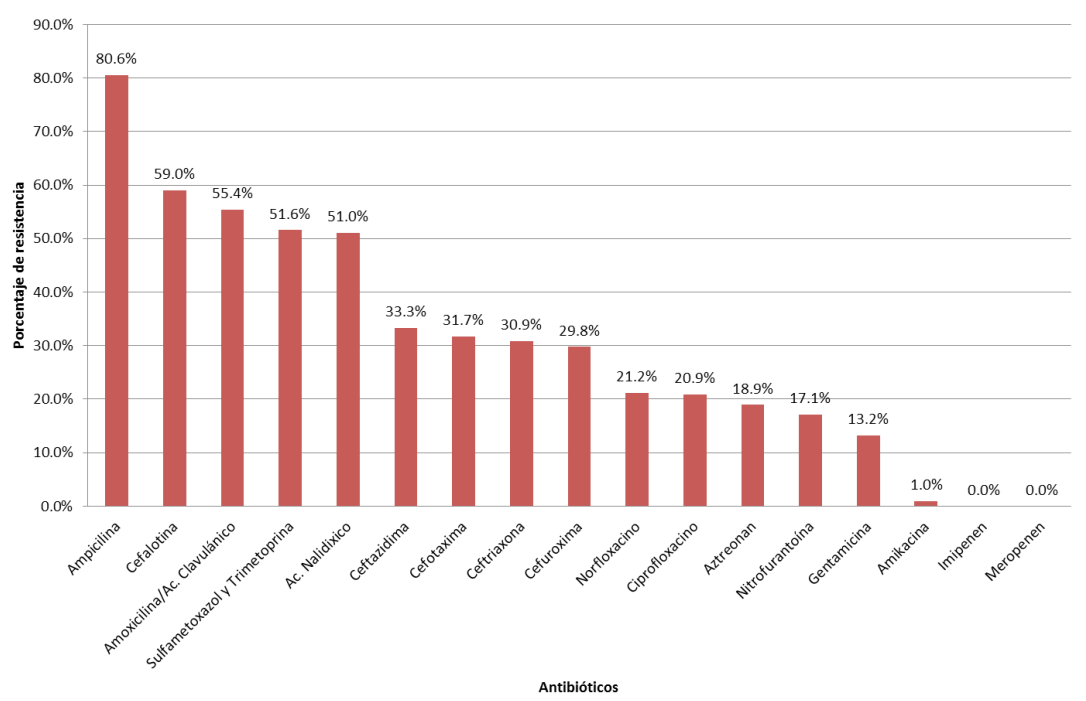

Gráfico 2. Resistencia antibiótica bacteriana en todos los grupos de pacientes (Primer episodio, recurrente o complicada).

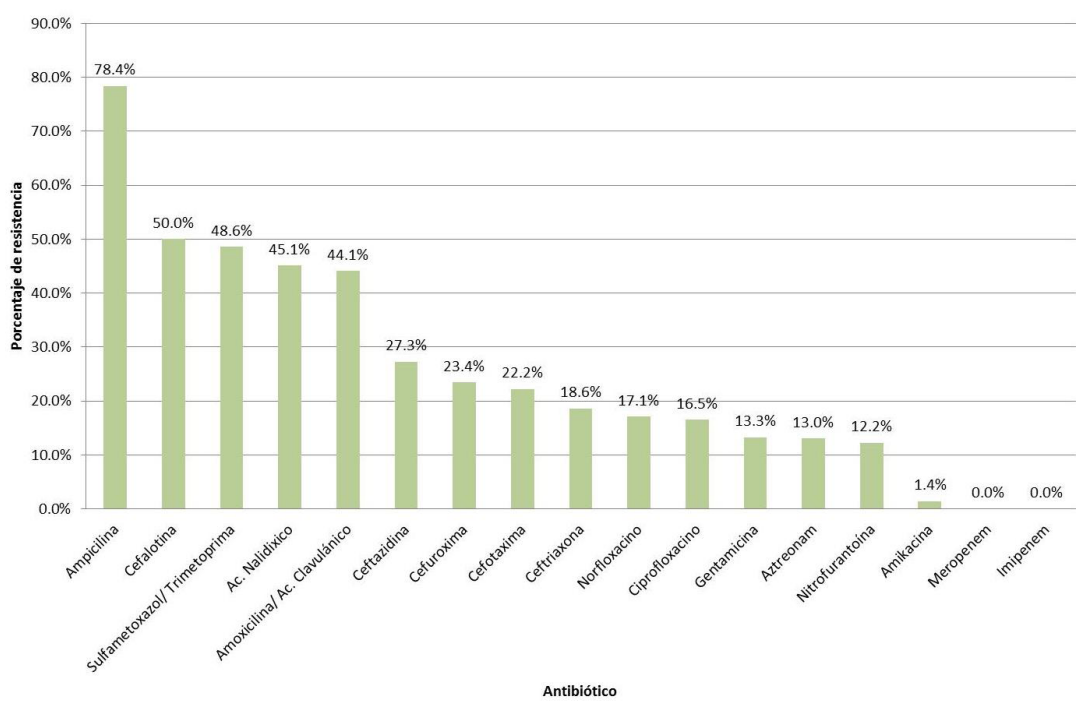

Gráfico 3. Resistencia antibiótica bacteriana en pacientes con primer episodio de infección urinaria.

mayor grupo de pacientes fueron mujeres menores de 1 año de edad (n=39) (Gráfico 1).

En 8 pacientes se consignó en la historia clínica el diagnóstico de malformación del sistema urinario, 7 eran mujeres ( 3 en pacientes con ITU complicada y 4 con ITU recurrente); y un varón con ITU complicada. Las malformaciones fueron vejiga neurogénica en 5 , hipoplasia renal en dos y un riñón en herradura. Adicionalmente 6 pacientes ( 5 mujeres y 1 varón) tuvieron el diagnóstico de ectasia piélica se encontró un caso de ITU complicada y 5 de ITU recurrente.

Escherichia coli fue el microorganismo aislado con más frecuencia; se aisló en 61(79,2\%) de pacientes con primer episodio (incluyendo 5 cultivos con Escherichia coli productora de $\beta$-lactamasa de espectro extendido (BLEE)); y 18 (53\%) en pacientes con ITU recurrente o complicada (incluyendo 4 aislamientos productoras de BLEE) Las bacterias aisladas se muestran en la tabla 2. Se aislaron $10(9 \%)$ cepas productoras de BLEE (Tabla 2).

La susceptibilidad antibiótica se muestra en la tabla 3. La resistencia bacteriana a los antimicrobianos de los aislamientos en todos los pacientes, en los pacientes con primera infección y en los casos de ITU complicada o recurrente, se pueden observar en los gráficos 2,3 y 4 , respectivamente. No se encontró resistencia a carbapenems. 


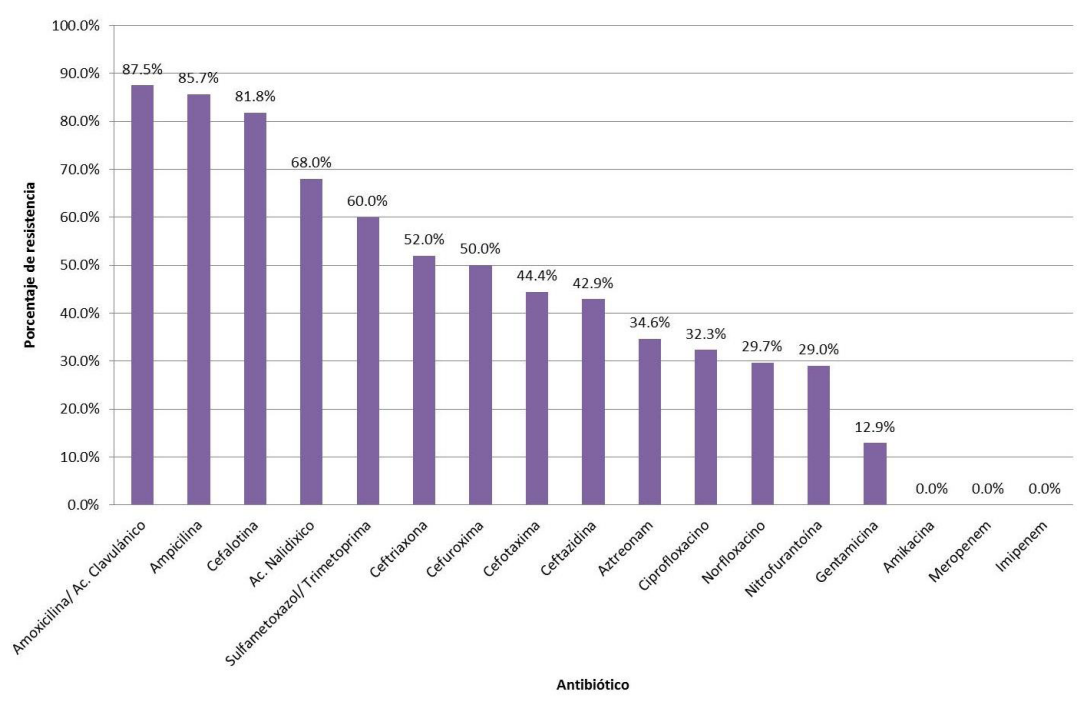

Gráfico 4. Resistencia antibiótica bacteriana en pacientes con infección urinaria complicada o recurrente.

\section{DISCUSIÓN}

Acorde con los datos demográficos extranjeros y locales, en nuestro estudio las mujeres son más afectadas con ITU que los varones (7). Más del 50\% de pacientes fueron lactantes mujeres, hallazgos similares se observó en otras series locales (8), en especial en el grupo con 1 año de edad. En nuestro estudio 31 mujeres y 3 varones tuvieron el diagnóstico de ITU recurrente o complicada.

La frecuencia de Escherichia coli en todas los tipos de ITU en niños fue de $65-90 \%$ (4). Resultados similares fueron encontrados por Chiarella y col. en nuestro medio (2).

En pacientes con ITU primer episodio, la resistencia (considerando a todos los microorganismos) para ampicilina fue mayor al $70 \%$ confirmando lo encontrado por Chiarella y col. en 1990, y Lucana y col. 2008 (8), lo que justificaría que ampicilina haya dejado de usarse en nuestro medio para el tratamiento de la ITU. Las cefalosporinas presentaron una resistencia de alrededor del $20 \%$, del mismo modo el sulfametoxazol/trimetoprima y la amoxicilina/ácido clavulánico tuvieron niveles de resistencia antibiótica mayores al $40 \%$, lo cual nos sugiere no utilizarlos en la terapia empírica inicial en pacientes con ITU. Por otro lado las fluoroquinolonas presentaron niveles de resistencia menores al $20 \%$, sin embargo el perfil de seguridad no está bien estudiado en niños. Los elevados porcentajes de resistencia de nuestro estudio para amoxicilina/ácido clavulánico podrían responder a una resistencia inducida por el uso no racional de antibióticos en la práctica pediátrica general.
En pacientes con ITU recurrente o complicada, amoxicilina/ácido clavulánico presentó una alta resistencia antibiótica del $87,5 \%$, del mismo modo las aminopenicilinas y las sulfas. Las cefalosporinas presentaron niveles de resistencia mayores al $40 \%$, este incremento también se observó en series extranjeras donde la resistencia a las cefalosporinas (cefotaxima, ceftazidima, cefepime) es reportada en niños que reciben terapia antibiótica profiláctica (9) (Gráfico 4). La aparición de cepas resistentes podría responder a la presencia de factores comórbidos o la exposición previa a las cefalosporinas generando mecanismos de resistencia en los microorganismos como la producción de $\beta$-lactamasas. No podemos confirmar esta hipótesis debido a que no se consignó información sobre profilaxis antibiótica. Por otro lado, en este grupo de pacientes con ITU complicada o recurrente encontramos que el norfloxacino y la ciprofloxacina tuvieron una resistencia de alrededor del $30 \%$, a pesar que ambos fármacos no son de uso común entre los pediatras.

De los antibióticos por vía oral estudiados en nuestra serie la nitrofurantoína tiene una sensibilidad mayor al $80 \%$ en todos los grupos de pacientes, cabe resaltar que la nitrofurantoína tiene excreción renal pero no alcanzan una concentración terapéutica en el suero por lo que no son recomendados en infantes febriles o niños pequeños con compromiso renal debido a que las concentraciones en el parénquima y en el suero son insuficientes para tratar episodios de pielonefritis o urosepsis, pero sí podrían utilizarse para casos de cistitis. Las sulfas se concentran adecuadamente en las vías urinarias, sin embargo la resistencia encontrada en nuestra serie es mayor al $50 \%$ en todos los grupos 
de pacientes por lo tanto no debe considerarse en el tratamiento empírico de la ITU en niños.

De los antibióticos por vía parenteral estudiados en nuestra serie las cefalosporinas de primera, segunda y tercera generación presentaron en todos los grupos de pacientes niveles de resistencia bacteriana cercanos al $30 \%$, estos resultados son menores a los reportados en nuestro medio por Lucana y col, (Tabla 4) lo que sugiere no considerarlos como terapia inicial sobre todo en pacientes con ITU complicada o recurrente. Los aminoglucósidos (amikacina, gentamicina) podrían ser apropiados agentes parenterales de primera línea para el tratamiento empírico de ITU en niños pero considerando que la resistencia a gentamicina fue del 13\% en todos los grupos de ITU. En el caso de carbapenems en todos los grupos de pacientes con ITU, ITU complicada o ITU recurrente presentaron una susceptibilidad del 100\% (imipenen, meropenen).

Las limitaciones del estudio fueron: 1) El tipo de diseño retrospectivo que no permitió detallar mayor información no consignada en los registros clínicos; 2) número limitado de pacientes sobre todo con ITU recurrente o complicada; 3) no se aplicaron otros métodos para la confirmación de mecanismos adicionales de resistencia bacteriana antibiótica y 4) no se utilizó el mismo número de discos en los urocultivos analizados.

En conclusión, Escherichia coli fue el microorganismo aislado con mayor frecuencia. Se obtuvieron niveles de resistencia mayor al $20 \%$ en las aminopenicilinas, sulfas, cefalosporinas de primera, segunda y tercera generación así como las quinolonas. Nitrofurantoína y los aminoglucósidos presentaron menores niveles de resistencia por lo que podrían ser utilizados como terapia empírica para los casos de cistitis y pielonefritis respectivamente.

\section{Declaración de financiamiento y conflictos de intereses:}

Los autores declaran no haber recibido financiamiento externo, ni la existencia de conflictos de interés.

\section{Correspondencia.}

Fernando Polanco Hinostroza.

Jr. Ignacio Merino 3911 - Int. 4 Piso

Los Olivos. Lima, Perú

Correo electrónico: fernando.polanco@upch.pe

\section{REFERENCIAS BIBLIOGRÁFICAS}

1. Prais D, Straussberg R, Avitzur Y. Bacterial susceptibility to oral antibiotics in community acquired urinary tract infection. Arch Dis Child. 2003; 88(3):215.

2. Chiarella P, Fukuda J, Chaparro E, Yi A. Infección del tracto urinario en pediatría: Etiología y tratamiento. Rev Med Hered. 1993; 4: 178-181.

3. Gonzales C, Jaulis J, Tapia E. Sensibilidad antibiótica de bacterias causantes de infecciones del tracto urinario en un hospital general: Enero-junio 2008. Rev Med Hered. 2009; 20 (1) 11-15.

4. Younis N, Al-Momani T, Al-Awaished F. Antibiotic resistance in children with recurrent or complicated urinary tract infection. J Nepal Med Assoc. 2009; 48 (173): 14-9.

5. Committee on Quality Improvement. Subcommittee pm Urinary Tract Infections. Practice parameter: the diagnosis, treatment, and evaluation of the initial UTI in febrile. Pediatrics. 1999; 103(4): 843-52.

6. Ministerio de Salud, Instituto Nacional de Salud. Manual de procedimientos para la prueba de sensibilidad antimicrobiana por el método de disco difusión. Lima: INS; 2002. Pag 35-36. (Citado el 12 de marzo del 2012). Disponible en: http://www. ins.gob.pe/repositorioaps/0/4/jer/-1/manua_ $1 \% 20$ sensibilidad.pdf

7. Chang SL, Shortliffe LD. Pediatric urinary tract infections. Pediatr Clin North Am. 2006; 53: 379400.

8. Lucana M, Llenera J. Etiología y sensibilidad antibiótica de infección del tracto urinario en menores de 4 años en el Instituto Nacional de Salud del Niño durante el año 2008. Tesis bachiller en Medicina. Lima. Universidad Peruana San Martín de Porres. 2011.

9. Prais D, Straussberg R, Avitzur Y, Nussinovitch M, Harel L, Amir J. Bacterial susceptibility to oral antibiotics in community acquired urinary tract infection. Arch Dis Child. 2003; 88(3): 215-218. 